\title{
MOG cell-based assay detects non-MS patients with inflammatory neurologic disease
}

\section{OPEN}

Patrick Waters, PhD* Mark Woodhall, PhD* Kevin C. O'Connor, PhD Markus Reindl, PhD Bethan Lang, PhD Douglas K. Sato, MD Maciej Juryńczyk, MD George Tackley, MBBCh Joao Rocha, MD Toshiyuki Takahashi, MD Tatsuro Misu, MD Ichiro Nakashima, MD Jacqueline Palace, MD Kazuo Fujihara, MD M. Isabel Leite, DPhil Angela Vincent, FRS

Correspondence to Dr. Waters: paddy.waters@ndcn.ox.ac.uk

Supplemental data at Neurology.org/nn

\section{ABSTRACT}

Objective: To optimize sensitivity and disease specificity of a myelin oligodendrocyte glycoprotein (MOG) antibody assay.

Methods: Consecutive sera ( $n=1,109)$ sent for aquaporin-4 (AQP4) antibody testing were screened for MOG antibodies (Abs) by cell-based assays using either full-length human MOG (FL-MOG) or the short-length form (SL-MOG). The Abs were initially detected by Alexa Fluor goat anti-human $\lg \mathrm{G}(\mathrm{H}+\mathrm{L})$ and subsequently by Alexa Fluor mouse antibodies to human IgG1.

Results: When tested at 1:20 dilution, 40/1,109 sera were positive for AQP4-Abs, 21 for SLMOG, and 180 for FL-MOG. Only one of the 40 AQP4-Ab-positive sera was positive for SLMOG-Abs, but 10 (25\%) were positive for FL-MOG-Abs ( $p=0.0069)$. Of equal concern, 48\% (42/88) of sera from controls (patients with epilepsy) were positive by FL-MOG assay. However, using an IgG1-specific secondary antibody, only 65/1,109 (5.8\%) sera were positive on FL-MOG, and AQP4-Ab- positive and control sera were negative. IgM reactivity accounted for the remaining anti-human $\lg \mathrm{G}(\mathrm{H}+\mathrm{L})$ positivity toward FL-MOG. The clinical diagnoses were obtained in 33 FL-MOG-positive patients, blinded to the antibody data. IgG1-Abs to FL-MOG were associated with optic neuritis ( $n=11)$, AQP4-seronegative neuromyelitis optica spectrum disorder $(n=4)$, and acute disseminated encephalomyelitis $(n=1)$. All 7 patients with probable multiple sclerosis (MS) were MOG-lgG1 negative.

Conclusions: The limited disease specificity of FL-MOG-Abs identified using Alexa Fluor goat antihuman $\lg G(H+L)$ is due in part to detection of IgM-Abs. Use of the FL-MOG and restricting to IgG1-Abs substantially improves specificity for non-MS demyelinating diseases.

Classification of evidence: This study provides Class II evidence that the presence of serum IgG1- MOG-Abs in AQP4-Ab-negative patients distinguishes non-MS CNS demyelinating disorders from MS (sensitivity 24\%, 95\% confidence interval [CI] 9\%-45\%; specificity 100\%, 95\% Cl 88\%-100\%). Neurol Neuroimmunol Neuroinflamm 2015;2:e89; doi: 10.1212/ NXI.0000000000000089

\section{GLOSSARY}

Abs = antibodies; $\mathbf{A D E M}=$ acute disseminated encephalomyelitis; $\mathbf{A Q P 4}=$ aquaporin-4; $\mathbf{C B A}=$ cell-based assay; $\mathbf{C l}=$ confidence interval; EDTA = ethylenediaminetetraacetic acid; FACS = fluorescent-activated cell sorting; FL-MOG = fulllength human MOG; LETM = longitudinally extensive TM; MOG = myelin oligodendrocyte glycoprotein; MS = multiple sclerosis; NMO = neuromyelitis optica; NMOSD = NMO spectrum disorder; ON = optic neuritis; PEI = polyethylenimine; SLMOG = short-length MOG; TM = transverse myelitis.

Antibodies (Abs) that bind the CNS-restricted membrane protein myelin oligodendrocyte glycoprotein (MOG) were first described by ELISA or Western blot predominantly in patients with multiple sclerosis (MS), but they have also been described in patients with bacterial or viral CNS inflammation or neuromyelitis optica (NMO). ${ }^{1-11}$ These findings were not reproducible using

\footnotetext{
*These authors contributed equally to the manuscript.

From the Nuffield Department of Clinical Neurosciences (P.W., M.W., B.L., M.J., G.T., J.R., J.P., M.I.L., A.V.), John Radcliffe Hospital, Oxford, UK; Department of Neurology (K.C.O.), Yale School of Medicine, New Haven, CT; Clinical Department of Neurology (M.R.), Innsbruck Medical University, Innsbruck, Austria; Department of Neurology (D.K.S., I.N.) and Department of Multiple Sclerosis Therapeutics (T.M., K.F.) Tohoku University School of Medicine, Sendai, Japan; and Department of Neurology (T.T.), Yonezawa National Hospital, Yonezawa, Japan. Funding information and disclosures are provided at the end of the article. Go to Neurology.org/nn for full disclosure forms. The Article Processing Charge was paid by the authors.

This is an open access article distributed under the terms of the Creative Commons Attribution-Noncommercial No Derivative 3.0 License, which permits downloading and sharing the work provided it is properly cited. The work cannot be changed in any way or used commercially.
} 
similar methods, ${ }^{12-18}$ but serologic findings and different experimental approaches suggested that MOG-Abs may be pathogenic. ${ }^{19-23}$ More-specific assays using soluble, tetramerized extracellular domain of native MOG identified Abs in a subset of patients with acute disseminated encephalomyelitis (ADEM) but rarely in adult-onset MS cases, now suggesting that the test could be of relevance for discriminating MS from other demyelinating syndromes. ${ }^{24}$ This was confirmed by cell-based assay (CBA) that also used a truncated MOG, in which MOGAbs were found in patients with aquaporin-4 (AQP4)-seronegative NMO but not those with MS..$^{25,26}$ CBA using full-length human MOG (FL-MOG) appears to be more sensitive, and a clinical phenotype of ADEM and AQP4-seronegative NMO spectrum disorder (NMOSD), often optic neuritis $(\mathrm{ON})$, is emerging. ${ }^{27-36}$ However, positivity in healthy individuals and patients with MS, even at relatively high serum dilutions (up to 1:640), affects its clinical use.

Figure 1 Flow diagram of the assays and the samples that were evaluated

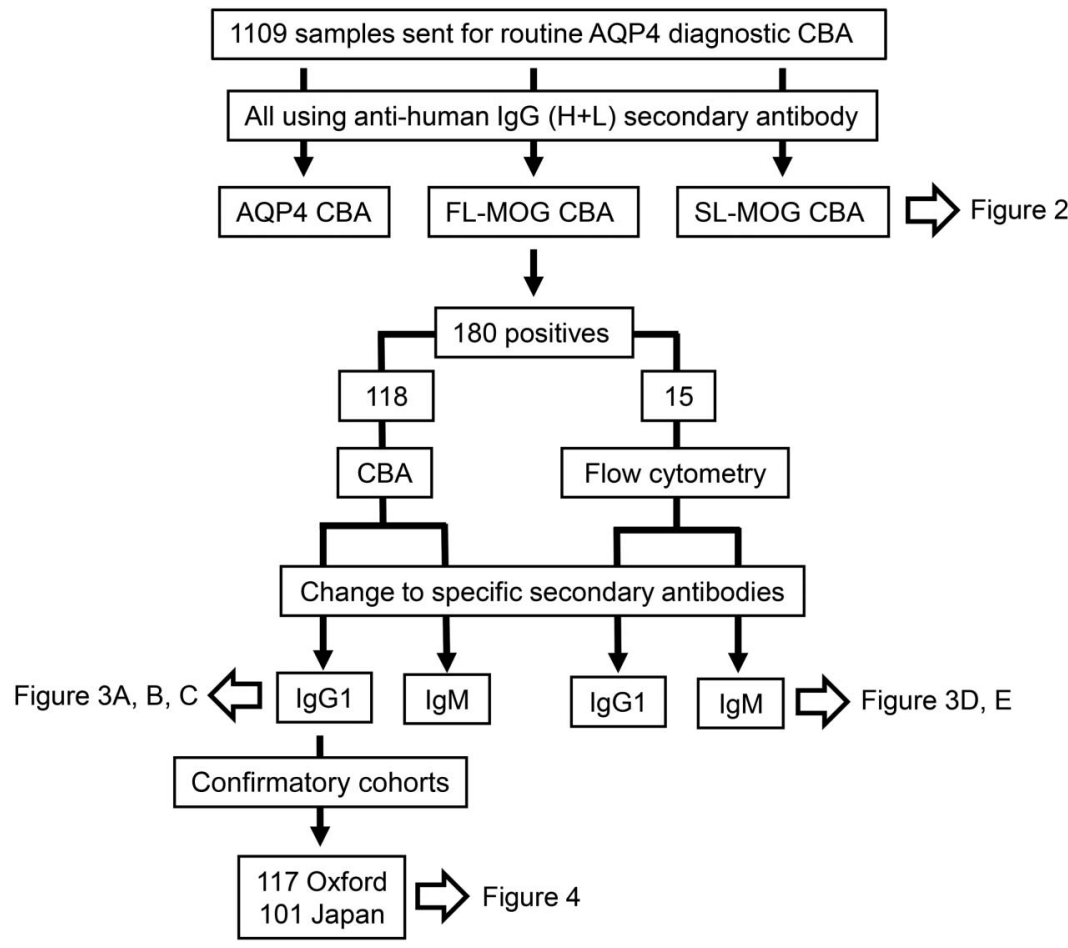

A total of 1,109 samples were initially screened at a serum dilution of 1:20 for antibodies to aquaporin-4 (AQP4), short-length MOG (SL-MOG), and full-length human MOG (FL-MOG). Different secondary antibodies were then evaluated on FL-MOG-positive serum samples by FLMOG cell-based assay (CBA) or flow cytometry. When the assay was established, 2 patient cohorts with clinical diagnoses from Oxford, UK and Sendai, Japan were used to calculate assay metrics.
Here we confirm that C-terminal truncation of the MOG antigen reduces assay sensitivity and that many of the low positive Abs found to bind to FL-MOG result from crossreactivity of the anti-human $\mathrm{IgG}$ secondary antibody with IgM Abs. Using IgG1-specific secondary antibody allows use of lower serum dilutions with FL-MOG, with improved specificity for patients with $\mathrm{ON}$, transverse myelitis (TM), AQP4-Ab-negative NMO, or ADEM.

METHODS Patients. Consecutive serum samples from 1,109 individuals sent for routine AQP4-Ab testing over 3 months were studied. Samples are sent to Oxford via clinical immunology laboratories with very limited or no clinical information. Sera from 118 of the 180 FL-MOG-positive samples were used to assess different secondary Abs, and 15/180 FL-MOG-seropositive samples were used for flow cytometry (a flow diagram of which samples were tested on the different assays is shown in figure 1). To assess the clinical relevance, a brief anonymized questionnaire was sent after the analyses to 48 identifiable referring clinicians requesting patient diagnosis, treatment responses, and relapses, if any. Controls were sera from previously archived cohorts. To validate the results, 2 other cohorts were screened. Patients seen at the National NMO Specialised Services who had already been tested for AQP4-Abs were tested for MOG-IgG1-Abs. After testing was completed, the diagnoses and follow-up times from the seropositive patients were obtained from a database. A further cohort of 101 Japanese patients with a range of demyelinating diagnoses (see Results) followed by or referred to Tohoku University Hospital and who had been previously tested for AQP4-Abs were tested for MOG-IgG1-Abs. All assays were carried out blinded to the clinical diagnoses.

Ethics. Ethics have been approved for the study of any patients whose samples have been referred to the Neuroimmunology laboratory in Oxford for diagnostic testing (Oxfordshire REC A; 07/Q1604/28 Immune factors in neurological disease). Since January 2010, data on all patients seen within the Oxford clinical NMO service have been entered prospectively into a clinical database and patient serum samples have been routinely tested for AQP4-Abs and MOG-Abs. The ethics committee of Tohoku University Graduate School of Medicine approved this study, and all participants provided written informed consent.

Constructs. The cloning of M23 isoform of human AQP4 has been described previously. ${ }^{7}$ FL-MOG was cloned into pIRES2-DsRed2 using the forward primer $\left(5^{\prime}-3^{\prime}\right)$ : gatcctcgagccaccatggcaagcttatcaagaccctctctg and the reverse primer $\left(5^{\prime}-3^{\prime}\right)$ : gatccccgggtcagaagggatttcgtagctcttcaagg. A C-terminal-truncated MOG construct was created from the full-length construct by insertion of a stop codon after Gly155 and excision of the remainder of the C-terminus. The 2 forms differ only in the intracytoplasmic domain (figure 2A).

Cell-based assays. HEK293T cells, polyethylenimine (PEI) transfected with human M23-AQP4, FL-MOG, or Cterminal-truncated human MOG (short-length MOG; SLMOG) were used as the substrate for live CBAs, which were performed as described elsewhere. ${ }^{7-9}$ Patient sera were tested at 1:20 dilution. The Alexa Fluor 488 goat anti-human $\operatorname{IgG}(\mathrm{H}+\mathrm{L})$ from Invitrogen (A1013, Carlsbad, CA) was used at 1:750 dilution. A semiquantitative scoring system was used: 0 , no binding; 1, low-level binding; $2-4$, increasing level of specific binding. 
Samples scoring $>1$ were considered positive. The average of 2 individual's scores is plotted (M.W., P.W.).

Subclasses. Alexa Fluor 488 mouse anti-human IgG1 (A10631, Invitrogen) and mouse anti-human IgM (A21215, Invitrogen), both at 1:500 dilution, or anti-human IgG3 (1:50 dilution, I7260, Sigma-Aldrich, Gillingham, UK) followed by Alexa Fluor 488 goat anti-mouse IgG (H + L; A11001, Invitrogen) were used as secondary or tertiary Abs. These assays were carried out as described previously except cells were fixed after the final antibody incubation.

Flow cytometry. A similar method to that used for detection of AQP4-Abs (as described in Waters et al. ${ }^{37}$ ) was used here for FLMOG detection. Briefly, HEK293T cells were transfected using PEI for 16 hours with the pIRES2-DsRed2 plasmid that contained the complementary DNA for FL-MOG. After washing and incubation for 24 hours at $37^{\circ} \mathrm{C}$ in $5 \% \mathrm{Co}_{2}$, the cells were trypsinized and resuspended in Dulbecco's modified Eagle's medium, $1 \%$ fetal calf serum, $1 \mathrm{mM}$ ethylenediaminetetraacetic acid (EDTA) (fluorescent-activated cell sorting [FACS] buffer) at $1.0 \times 10^{6} \mathrm{cells} / \mathrm{mL}$. The cells were rotated at $4^{\circ} \mathrm{C}$ for 1 hour. All further steps were carried out at $4^{\circ} \mathrm{C}$. Patient serum (diluted 1:10 in FACS buffer) was mixed with $1.0 \times 10^{5}$ cells $(100 \mu \mathrm{L})$. After rocking for 1 hour, the cells were washed, and bound IgG was detected with Alexa Fluor 488 goat anti-human IgG (diluted 1:500 in FACS buffer), Alexa Fluor 488 anti-human IgG1, or Alexa Fluor anti-human IgM for 30-45 minutes. The cells were washed, resuspended in $400 \mu \mathrm{L}$ phosphate-buffered saline $/ 2 \mathrm{mM}$ EDTA, and analyzed by FACScalibur. The level of transfection was determined by measuring DsRed intensity (PE-Texas red channel) in live cells (figure 3D, y-axis). Two gates were created: the upper gate captured cells expressing high levels of DsRed; the lower gate captured untransfected or poorly transfected cells and served as a negative control for each sample (figure 3Da). Bound $\operatorname{IgG}$ was measured in the green channel (a shift to the right on the $\mathrm{x}$-axis). A score for each serum was determined by subtracting the median green fluorescence in the lower gate from the median green fluorescence in the upper gate.

Statistics. A 2-tailed Wilcoxon matched-pairs signed-rank test was used to compare the FL-MOG and SL-MOG assays. The Mann-Whitney unpaired 2-tailed $t$ test or Fisher exact test was used to compare groups ( $p<0.05$ was considered significant).

Primary research question. Does this MOG assay using an anti-human IgG1-specific secondary antibody identify a

Figure 2 Antibodies to MOG detected with anti-human IgG $(\mathrm{H}+\mathrm{L})$ as the secondary antibody

\section{A. Myelin oligodendrocyte glycoprotein (MOG)}

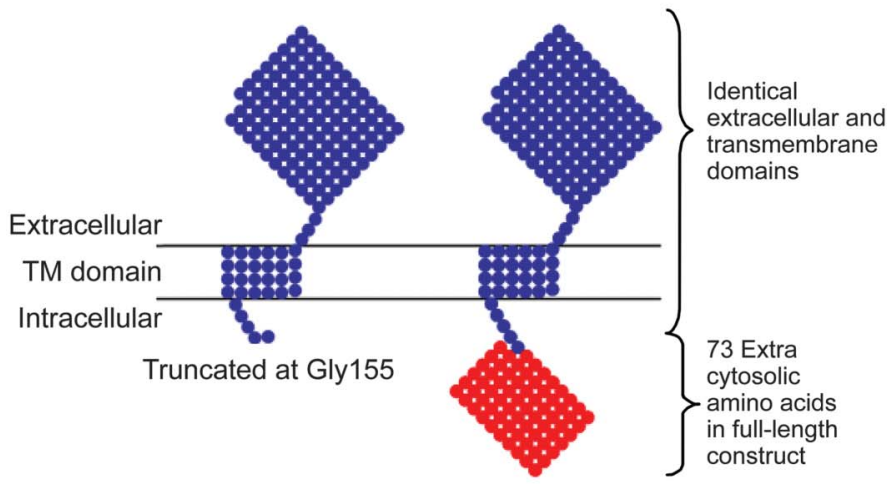

Short-length MOG Full-length MOG

C

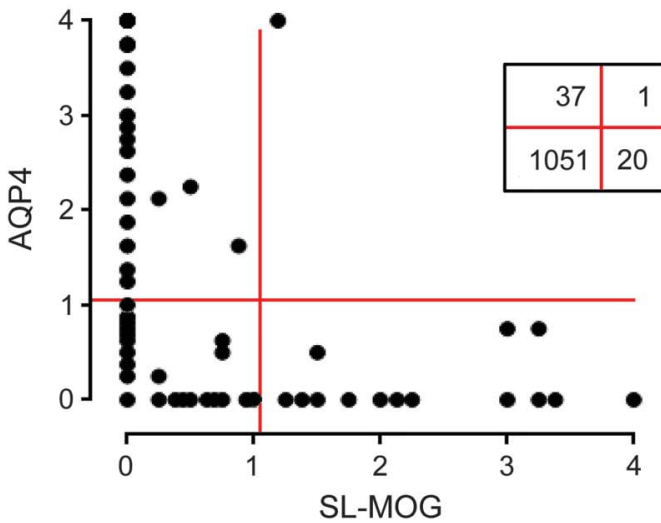

B
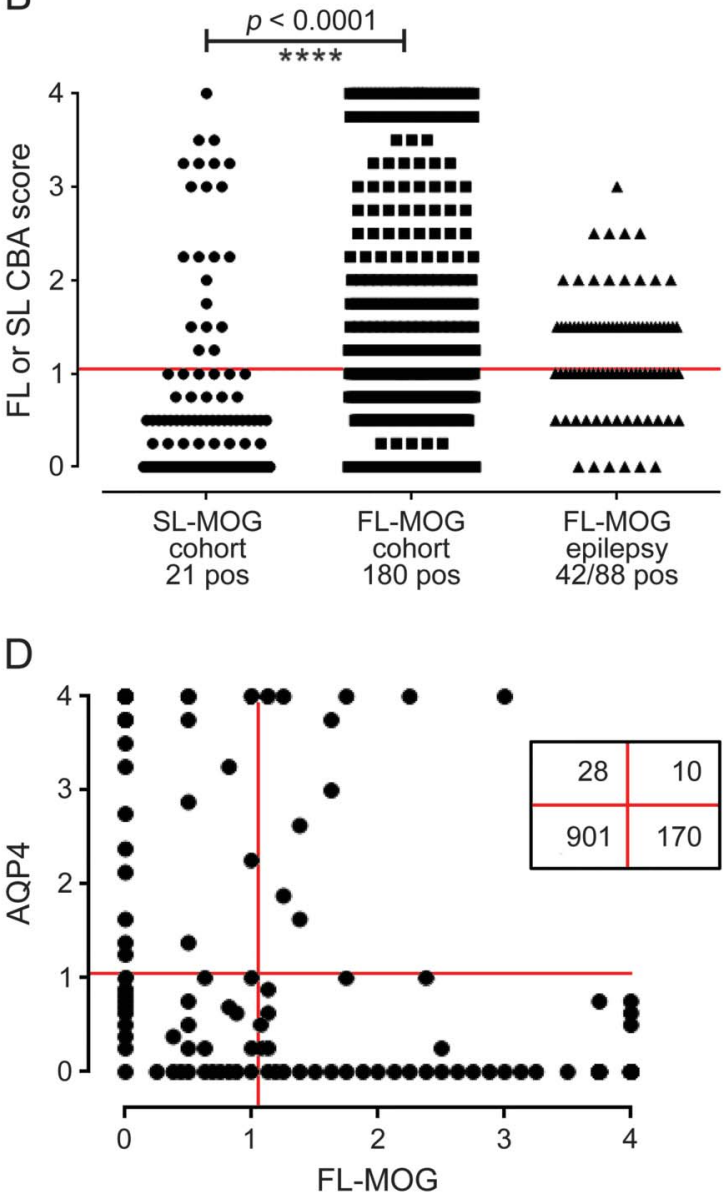

(A) Schematic of the human MOG proteins tested. The extracellular and transmembrane domains are identical, but the short-length MOG (SL-MOG) is 73 amino acids shorter at the C-terminus than full-length MOG (FL-MOG). (B) Screening 1,109 consecutive samples sent for aquaporin-4 (AQP4) antibody testing. With anti-human IgG $(\mathrm{H}+\mathrm{L})$ as the secondary antibody, 21 SL-MOG- positive samples and $180 \mathrm{FL}-\mathrm{MOG}$-positive samples were identified; however, a cohort of epilepsy sera demonstrates the striking lack of specificity in the FL-MOG assay. Comparing the AQP4 seropositivity in the 2 MOG assays, $1 / 38$ AQP4-positive samples were also positive for SL-MOG antibodies (C), compared with 10/38 for FL-MOG antibodies (D). CBA = cell-based assay. 

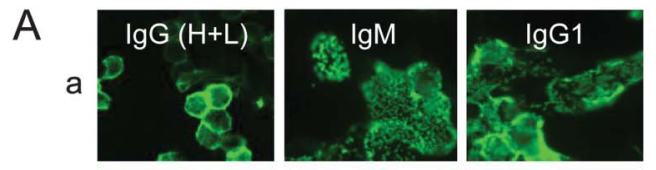

$\mathrm{b}$
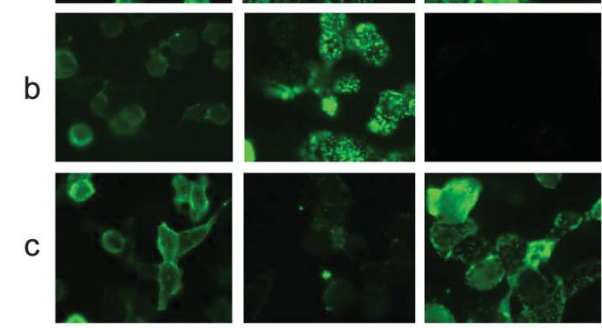

Con
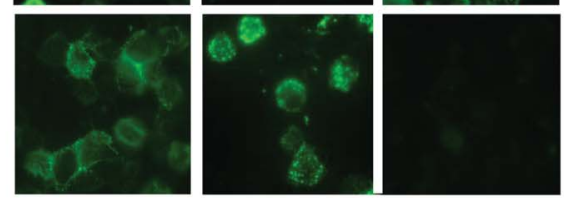

D.a

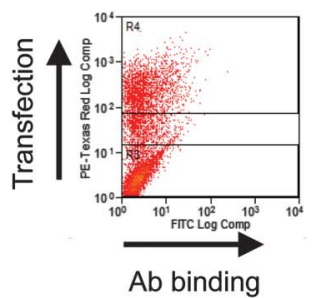

D.b
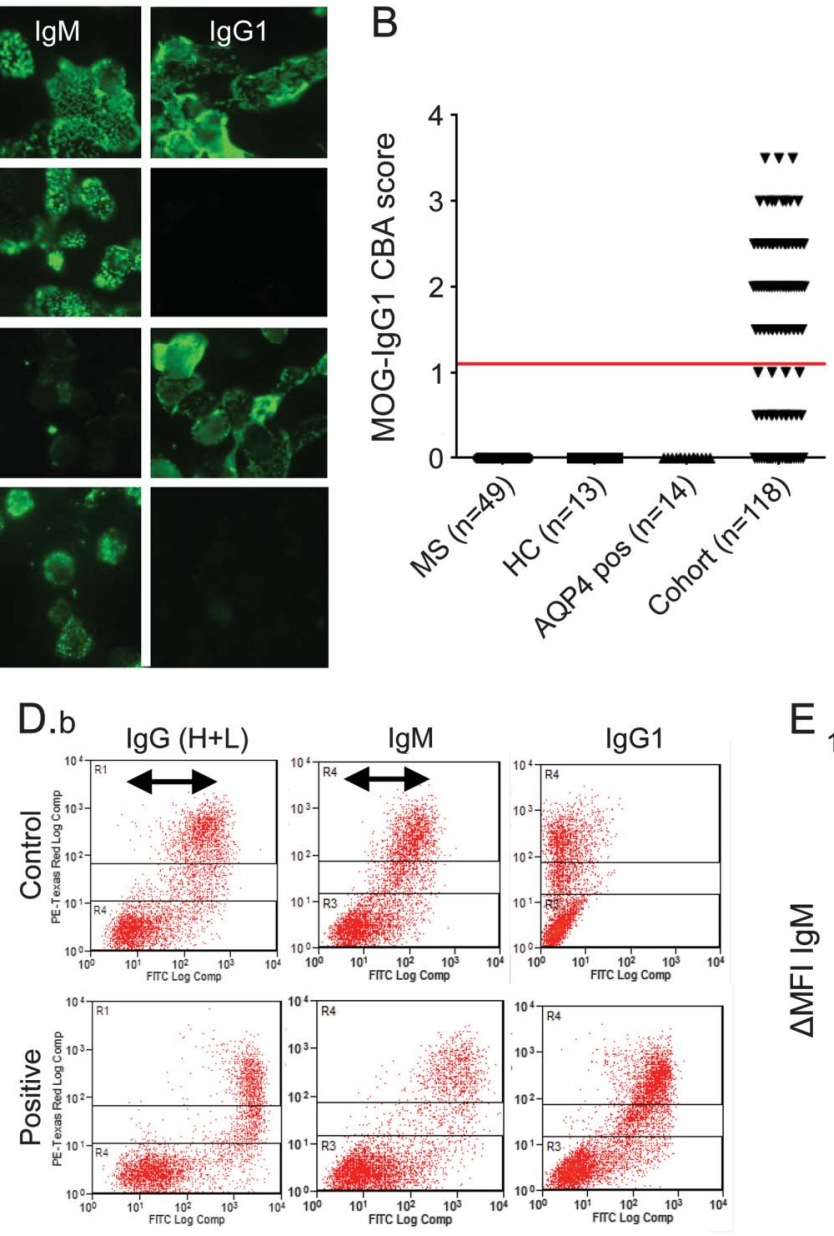

C
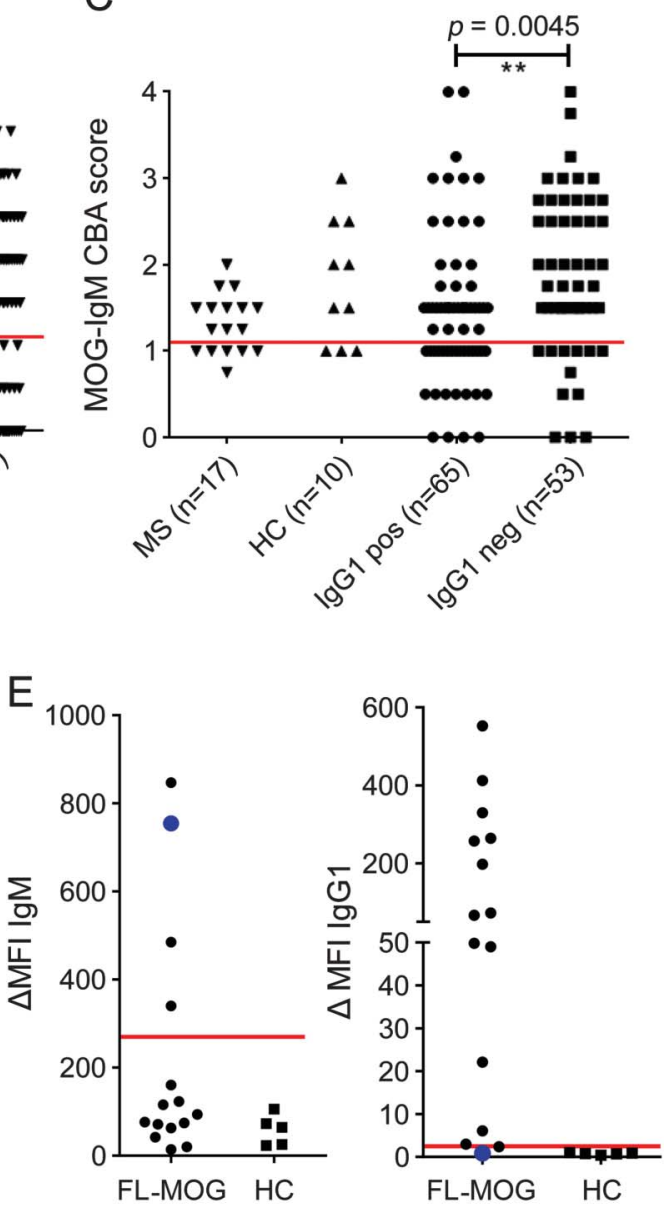

(A) Comparison of binding to full-length myelin oligodendrocyte glycoprotein (FL-MOG) using anti-human IgG (H + L), anti-lgM, or anti-lgG1 secondary antibodies with 3 different test sera (a-c) and a healthy control serum (con). (B) IgM and (C) IgG1 binding scores for patients and healthy controls (HC). (D.a) PIRES2-DsRed2-FL-MOG transiently transfected HEK cells are separated into cells that express MOG and DsRed2 well (in the upper section of the graph) or poorly or not at all (lowest section of the graph). (D.b) Healthy control sera (upper panels) causes a specific shift in the MOG-transfected cells compared to the untransfected cells when anti-human IgG $(\mathrm{H}+\mathrm{L})$ or anti-human IgM secondary antibodies are used (arrows), but not when anti-human IgG1 secondary antibodies are used. The lower panels show higher shifts in sera positive for FL-MOG antibodies compared to controls in the upper panel. (E) Fifteen samples that were $\lg \mathrm{G}(\mathrm{H}+\mathrm{L})$ positive and 5 healthy controls were tested on flow cytometry with anti-lgM or lgG1. A high cutoff is generated with anti-human IgM secondary antibody ( $\triangle \mathrm{MFI}$ of 270 ) vs a $\triangle \mathrm{MFI}$ of 2.5 for the anti-human IgG1 antibody. Of note, one lgM-positive patient is IgG1 negative (blue circle). $\mathrm{Ab}$ = antibody; AQP4 = aquaporin-4; $\mathrm{CBA}$ = cell-based assay; MFI = mean fluorescence intensity; MS = multiple sclerosis.

subgroup of AQP4-antibody-seronegative patients with a nonMS CNS demyelinating disease?

This study provides Class II evidence that the presence of serum IgG1-Abs specific for MOG can distinguish AQP4-Abnegative patients with non-MS CNS demyelinating diseases from those with MS. The Japanese patients were used to calculate the assay metrics: 6 of 25 AQP4-Ab-negative patients with non-MS demyelinating diseases were MOG-IgG1 positive, for a sensitivity of $24 \%$ (95\% confidence interval [CI] 9\%-45\%), and 0 of 27 patients with MS were MOG-IgG1 positive, for a specificity of $100 \%$ (95\% CI 88\%-100\%).

RESULTS Out of 1,109 samples sent for diagnostic testing for AQP4-Abs, 40 sera were positive at 1:20 dilution. The SL-MOG assay detected Abs in 21 patients, including 1 (low positive) who was strongly positive for AQP4 (figure 2, B and C). However, the FL-MOG assays detected antibodies in 180 sera $(16 \%$ of the test cohort), and 10 of these sera were also positive for AQP4-Abs (figure 2D). Positive results for FL-MOG were also found in 42/88 sera from patients with epilepsy (48\%, figure $2 \mathrm{~B}$ ).

Control groups and 118/180 FL-MOG-positive sera that were available were retested by CBA using either anti-IgG1 or anti-IgM class-specific secondary Abs (figure 3). With anti-IgM, 101/118 test sera, $7 / 10$ healthy individuals, and 11/17 patients with MS were positive. The secondary antibody alone did not bind to FL-MOG-transfected HEK cells, and the control sera were negative on AQP4-transfected cells. With anti-IgG1, by contrast, only 65 of 118 sera had scores of greater than 1, and negative results were found in 49 patients with MS, 13 healthy sera, and 14 AQP4-Abpositive controls (figure 3C). 


\begin{tabular}{|c|c|c|c|c|c|c|c|c|}
\hline Table 1 & Antibody suk & ass speci & ty, $\lg G(H+$ & nt titration, SL-MOG cell-based assay s & re, sex, age at tes & g, and clinical description 0 & atients & \\
\hline Isotype & $\begin{array}{l}\lg G(H+L) \\
\text { endpoint titer }\end{array}$ & $\begin{array}{l}\text { SL-MOG } \\
\text { score }\end{array}$ & Sex, age, y & $\begin{array}{l}\text { Presentation or initial } \\
\text { diagnosis }\end{array}$ & Diagnosis & Treatment & Recovery & Relapse \\
\hline \multirow[t]{17}{*}{$\lg G 1$} & 1,200 & 4.0 & M, 32 & NMO & NMOSD & IVMP and steroid taper, PEX & Substantial & No \\
\hline & 800 & 0 & $M, 23$ & BON & rON & IVMP and steroid taper & Partial & No \\
\hline & 1,600 & 0 & $F, 36$ & Sequential BON & BON & IVMP and steroid taper & No & Yes \\
\hline & 800 & 0 & $F, 38$ & BON & BON & IVMP & Good & No \\
\hline & 200 & 0 & $F, 54$ & CRION & CRION & Steroids, cyclosporin, MMF & Yes & Yes \\
\hline & 300 & 0 & M, 55 & NMO historic case & NMOSD pre AQP4 & Steroids, azathioprine & Yes & Yes \\
\hline & 3,200 & 3.0 & $F, 48$ & RON & rON & Steroids, azathioprine & Incomplete & No \\
\hline & 3,200 & 1.0 & $F, 45$ & NMOSD-like & NMOSD & None & Substantial & No \\
\hline & 200 & 0 & $M, 47$ & BON & BON & Steroids only & Yes & No \\
\hline & 200 & 0 & $F, 57$ & Tumefactive lesions, ? CNS vasculitis & Vasculitis? & Steroids, cylcophosphamide & Yes & No \\
\hline & 800 & 2.5 & $F, 39$ & ON & ON & Steroids only & Very good & No \\
\hline & 1,200 & 0 & F, 3.3 & ADEM & ADEM & IVMP & Full & No \\
\hline & 1,600 & 0 & $F, 29$ & ON & ON & None & Partial & Not clear \\
\hline & 800 & 3.5 & $F, 67$ & NMO-like but AQP4 antibody negative & rLETM & Steroids only & Good & $\begin{array}{l}\text { Not after } \\
\text { treatment }\end{array}$ \\
\hline & 300 & 0 & $F, 33$ & BON & BON & Steroids only & Very good & No \\
\hline & 800 & 0 & $F, 28$ & Sequential BON & rBON & Steroids only & Yes (third episode) & No \\
\hline & 100 & 0 & $\mathrm{M}, 30$ & $\mathrm{rBON}$ & rON & None & Spontaneous & Yes \\
\hline $\lg \mathrm{G} 3$ & 3,200 & 0 & $M, 51$ & ON, myelitis, patchy cord lesions & Probable MS & IVMP & Full & No \\
\hline \multirow[t]{6}{*}{$\lg M$} & 25 & 0 & $\mathrm{~F}, 50$ & $\begin{array}{l}6 \text { years pain, aching, fatigue, visual } \\
\text { disturbance, ? TM }\end{array}$ & Other & Steroids only & No & \\
\hline & 75 & 0 & $\mathrm{~F}, 30$ & $\begin{array}{l}\text { Single episode ON, some focal } \\
\text { WM lesions }\end{array}$ & ON & None & Spontaneous & No \\
\hline & 20 & 0 & $F, 34$ & $\begin{array}{l}\text { Tumefactive MS, homonymous } \\
\text { hemianopia, ON, cord lesions; } \\
\text { OCB positive }\end{array}$ & Probable MS & Steroids and DMT & Yes & Yes \\
\hline & 20 & 0 & $F, 30$ & Probable MS & Probable MS & None & Yes but not full & Yes \\
\hline & 20 & 0 & $M, 44$ & Probable MS, many previous minor events & Probable MS & None & Partial & Yes \\
\hline & 20 & 0 & $F, 24$ & $\begin{array}{l}\text { Pain and tingling, perineal numbness, } \\
\text { bladder disturbance, patchy cord } \\
\text { lesions }\end{array}$ & $\begin{array}{l}\text { Probable MS, } \\
\text { probable CIS }\end{array}$ & Steroids only & Yes & No \\
\hline
\end{tabular}




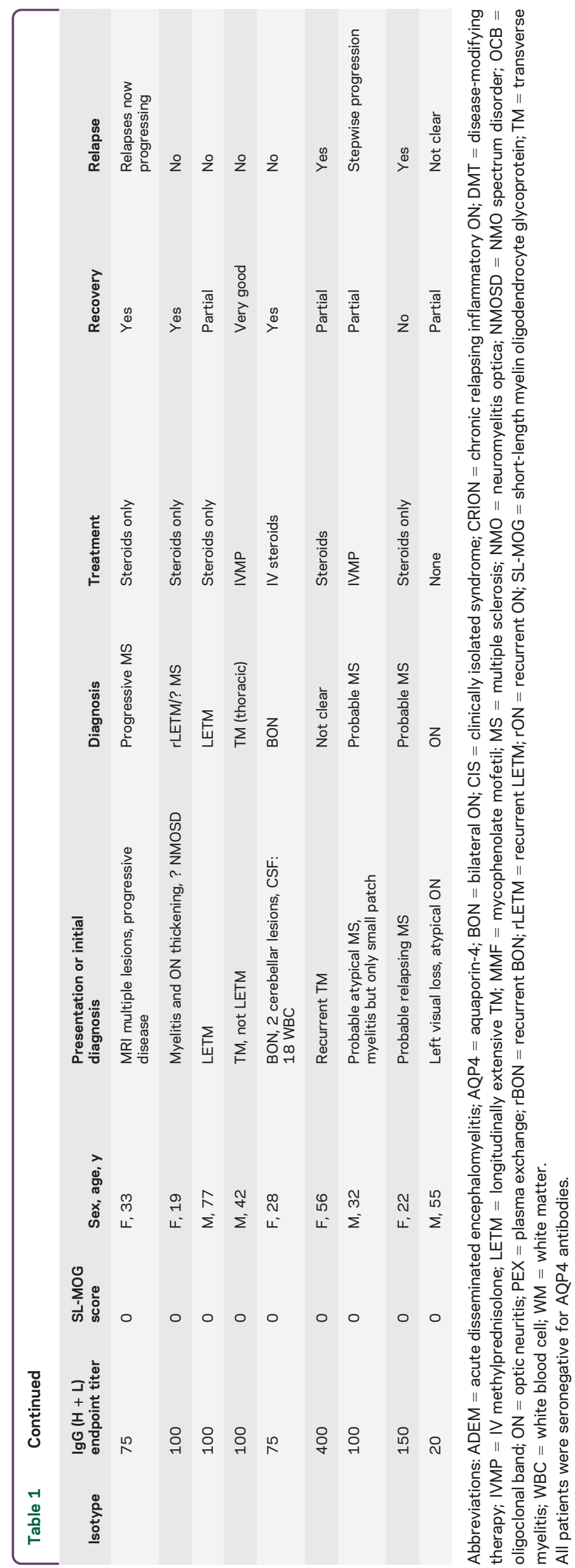

To further examine the lack of specificity in this assay, a group of 15 FL-MOG-seropositive samples and 5 healthy controls were tested by flow cytometry (figure 3D). IgG in healthy control sera bound to FLMOG-transfected cells when compared to the untransfected control cells in the same test sample when using anti-human $\operatorname{IgG}(\mathrm{H}+\mathrm{L})$ or anti-human $\operatorname{IgM}$ secondary Abs, but not with the anti-human IgG1 secondary antibody (figure 3D, horizontal arrows). Using the median score +6 SDs of the 5 healthy control sera, very different cutoffs were generated: 270 for the IgM antibody and 2.5 for the IgG1 antibody. One sera (large blue circle) demonstrated strong positivity using anti-human IgM secondary antibody but was negative for IgG-Abs (IgG3, 4 were also negative on this sample; data not shown).

Clinical phenotypes. Questionnaires on 38/48 patients (selected because the referring clinician could be identified) who were positive for $\operatorname{IgG}(\mathrm{H}+\mathrm{L})$ Abs were returned, but complete IgG1 and IgM antibody results were only available in 33 (17 IgG1-specific, 1 IgG3, and 15 IgM only). The isotype, FL-MOG endpoint titers, SL-MOG scores, and clinical diagnoses are shown in table 1. Seven patients with MS were positive with anti-human $\operatorname{IgG}(\mathrm{H}+\mathrm{L})$ or anti-IgM but not with anti-IgG1. In contrast, all of the anti-IgG1-positive patients had a clinical diagnosis of non-MS inflammatory demyelinating $\mathrm{CNS}$ disease. ON was more common with IgG1MOG-Abs (11/17 vs $3 / 15 ; p=0.02)$. In addition, one 51-year-old male patient with $\mathrm{ON}$ and myelitis with patchy cord lesions and high levels of $\mathrm{IgG} 3$ antibodies (endpoint titer of 3,200) was diagnosed with probable MS.

The majority of patients in each group substantially improved (13/17 IgG1 group vs 7/13 IgM only), and relapses were found in both groups (5/16 IgG1 and 6/12 IgM only).

Confirmatory cohorts. AQP4-seropositive NMOSD patients (37 NMO, $11 \mathrm{TM}, 33 \mathrm{ON}$ ) seen by the Oxford NMO service were negative for MOG-IgG1Abs; however, 23 AQP4-seronegative patients (8 NMO, 1 TM, 9 ON, 1 ON + TM, 4 ADEM) were MOG-IgG1 positive (figure $4 \mathrm{~A}$, table 2). Thirteen patients with NMO were double seronegative. Hence, of the 58 patients seen in Oxford that fulfill the 2006 Wingerchuk criteria for NMO, 37 (63.8\%) are AQP4 seropositive, 8 (13.8\%) MOG-IgG1 positive, and $13(22.4 \%)$ double seronegative.

A second cohort of 101 Japanese patients with inflammatory CNS diseases was screened with antiIgG1/FL-MOG without knowledge of the clinical phenotype or AQP4 status. None of the AQP4seropositive patients (28 NMO, 5 recurrent ON, 6 

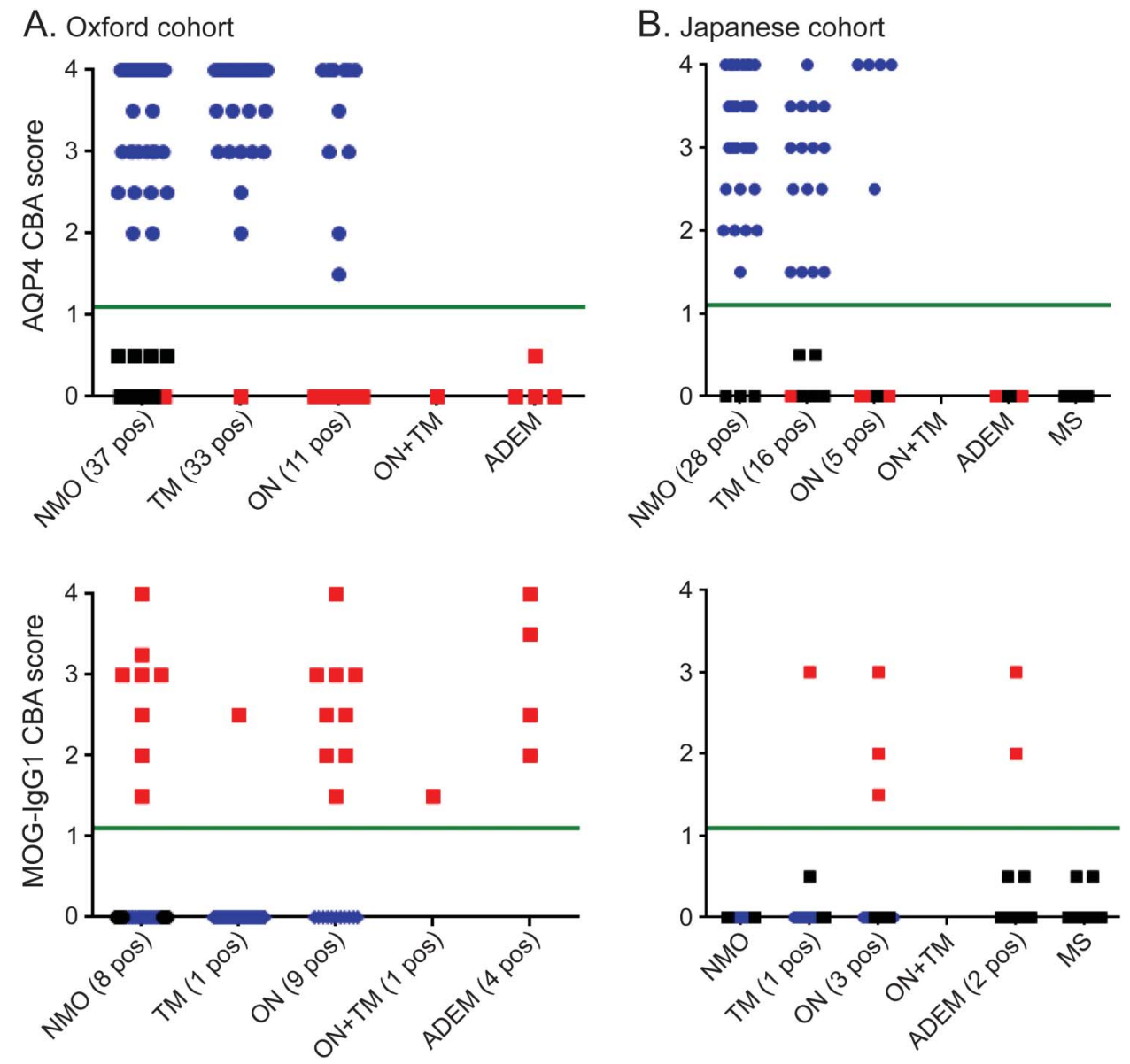

(A) All 81 aquaporin-4 (AQP4)- seropositive patients (blue) from the Oxford National neuromyelitis optica (NMO) service were negative for IgG1 antibodies to myelin oligodendrocyte glycoprotein (MOG); however, 23 AQP4-seronegative patients were identified as MOG-lgG1 seropositive (red). Of the 58 patients with NMO, 37 (63.4\%) were AQP4 seropositive, 8 (13.8\%) were MOG-IgG1 seropositive, and 13 (22\%) were double seronegative. (B) A second cohort from Japan was screened blinded to clinical information. None of the 49 AQP4-seropositive patients (blue) or 27 patients with multiple sclerosis (MS) were positive for MOG antibodies, but 6/25 patients with acute disseminated encephalomyelitis (ADEM), transverse myelitis (TM), optic neuritis (ON), or AQP4-seronegative NMO were MOG antibody positive (red). CBA = cell-based assay.

monophasic longitudinally extensive TM [LETM], 10 recurrent LETM) were MOG-IgG1 positive, but 6 samples had IgG1-MOG-Abs, with a clinical diagnosis of bilateral ON (3/3), monophasic LETM (1/10), or $\operatorname{ADEM}(2 / 11)$. The remainder of the cohort was double seronegative (3 NMO, 4 recurrent ON, 3 monophasic LETM, $27 \mathrm{MS}$, and 9 ADEM (figure 4). In contrast to the Oxford cohort, in which 8/23 AQP4seronegative NMO patients were MOG-IgG1 positive, none of the 3 AQP4-seronegative NMO patients from Tohoku were MOG-IgG1 positive. The majority of the MOG-IgG1-seropositive patients had a single attack and good recovery after steroid treatment, but 2 children with ADEM relapsed (table 2).

DISCUSSION MOG-Abs have been detected using different methods, which affects the patient groups that are identified as seropositive. Initially, using peptide Western blots or ELISAs, patients with MS or viral or bacterial encephalitis were identified as MOG seropositive. More recently, the extracellular domain of native MOG has been used in immunoprecipitation assays in which the majority of patients with MS were seronegative but one-third of patients with ADEM were seropositive. The advent of the CBA enabled native human MOG to be expressed on the cell surface as a target for these Abs. Unfortunately, sera from many healthy individuals diluted 1:20 were seropositive using this assay; therefore, a "high-titer" serum cutoff of 1:160 is used to differentiate patient cohorts from healthy individuals. A few patients with MS, AQP4seropositive patients, and healthy controls are still positive using this "high-titer" cutoff. ${ }^{30}$

We confirm the lack of disease specificity of the MOG CBA at 1:20: $16 \%$ of sera sent for AQP4 


\begin{tabular}{|c|c|c|c|c|c|}
\hline \multirow[t]{2}{*}{ Table 2} & \multicolumn{5}{|c|}{$\begin{array}{l}\text { Demographics, diagnoses, treatment, and response to treatment in the confirmatory cohorts tested } \\
\text { from Oxford and Japan }\end{array}$} \\
\hline & Sex, age, y & Diagnosis & Treatment & Recovery & Relapse \\
\hline \multirow[t]{23}{*}{ Oxford } & $F, 12$ & ADEM & IVMP + steroid tapering & Complete & No \\
\hline & $F, 6$ & ADEM & Acyclovir + IVlg followed by oral steroids & Substantial & No \\
\hline & $\mathrm{M}, 3$ & ADEM ON & $\begin{array}{l}\text { Steroids, IVIg, and PEX, then azathioprine } \\
\text { and prednisolone }\end{array}$ & Substantial & Yes \\
\hline & $M, 27$ & ADEM, LETM & IVMP then oral steroids & Partial & Yes \\
\hline & $F, 37$ & BON & IVMP and oral steroids & Substantial & Yes \\
\hline & M, 33 & BON & IVMP + steroid tapering and PEX & Partial & No \\
\hline & $M, 4$ & BON & IVMP + steroid tapering & Substantial & No \\
\hline & $F, 59$ & LETM & IVMP + steroid tapering & Complete & No \\
\hline & $F, 34$ & NMO & IVMP, oral steroids & Substantial & Yes \\
\hline & $F, 23$ & NMO & None & Complete & Yes \\
\hline & $\mathrm{M}, 16$ & NMO & IVMP + steroid tapering & Partial & Yes \\
\hline & $M, 36$ & NMO & IVMP + steroid tapering, azathioprine & Partial & Yes \\
\hline & $M, 24$ & NMO & IVMP, oral steroids, azathioprine & Partial & Yes \\
\hline & $\mathrm{M}, 31$ & NMO & IVMP, PEX, oral steroids & Complete & No \\
\hline & $F, 34$ & NMO & IVMP, oral steroids & Substantial & Yes \\
\hline & $M, 17$ & NMO & IVMP, oral steroids & Substantial & Yes \\
\hline & $F, 14$ & ON & IVMP, oral steroids & Substantial & No \\
\hline & $F, 54$ & ON brain & IVMP, oral steroids, MMF & Partial & Yes \\
\hline & M, 27 & ON TM brain & IVMP, oral steroids, interferon $\beta$ & Partial & Yes \\
\hline & $F, 43$ & RION & IVMP, oral steroids, methotrexate & None & Yes \\
\hline & $F, 42$ & RION & IVMP, methotrexate, oral steroids & Partial & Yes \\
\hline & $M, 8$ & RION & IVMP, oral steroids, PEX, azathioprine & Partial & Yes \\
\hline & M, 34 & RION & None & Partial & Yes \\
\hline \multirow[t]{6}{*}{ Japan } & $M, 28$ & BON & IVMP + steroid tapering & Yes & No \\
\hline & $M, 70$ & BON & IVMP + steroid tapering & Yes & No \\
\hline & $M, 37$ & BON & IVMP + steroid tapering & Yes & No \\
\hline & $M, 50$ & Myelitis & IVMP & Yes & No \\
\hline & $M, 1.3$ & ADEM & IVMP + steroids & Yes & Yes \\
\hline & $F, 9$ & ADEM & IVMP + steroids & Yes & Yes \\
\hline
\end{tabular}

Abbreviations: $\mathrm{ADEM}=$ acute disseminated encephalomyelitis; $\mathrm{BON}=$ bilateral $\mathrm{ON}$; Brain = changes seen on brain MRI; IVlg = IV immunoglobulin; IVMP = IV methylprednisolone; LETM = longitudinally extensive TM; MMF = mycophenolate mofetil; $\mathrm{NMO}$ = neuromyelitis optica; $\mathrm{ON}$ = optic neuritis; PEX = plasma exchange; RION = relapsing inflammatory ON; $\mathrm{TM}=$ transverse myelitis.

None of the patients were aquaporin- 4 antibody positive.

testing and nearly $50 \%$ of patients with epilepsy were MOG positive. Similar positivity is seen in healthy control sera (data not shown). The secondary antibody $\operatorname{IgG}(\mathrm{H}+\mathrm{L})$ binds to more than the IgG antibody class, which appears to affect the MOG CBA more than CBAs in which other targets are expressed (e.g., AQP4, GlyR). When examined by flow cytometry, the "low- level" binding of healthy control sera visualized by CBA is replicated by a specific shift in the MOG-transfected cells when compared to the untransfected or poorly transfected cells. Two advantages of this quantitative system are that the background binding can be quantified and a cutoff can be generated based on healthy sera. Using 6 SDs above the mean of a group of healthy control sera, the $\operatorname{IgG}(\mathrm{H}+\mathrm{L})$ antibody gave a cutoff of 470 , with the top of the assay 10 times this cutoff value (data not shown). Using the same control and test samples, the anti-human IgM secondary antibody gave a cutoff of 270 , with the top of the assay only 3 times the cutoff and with very few positive samples, whereas the antihuman IgG1 antibody cutoff was just 2.5 and the top of the assay was 220 times this cutoff. The specificity of the MOG-IgG1 assay was confirmed by CBA in 
which 49 patients with MS, 13 healthy control sera, and 14 AQP4-seropositive serum samples were all negative at a dilution of 1:20, whereas 65 of the 118 samples that were positive using $\operatorname{IgG}(\mathrm{H}+\mathrm{L})$ secondary antibody remained positive using the IgG1-specific antibody. None of the MOG-IgG1-positive patients with an available clinical diagnosis had MS, suggesting that this assay may be valuable to help distinguish patients with MS from those with ADEM or AQP4Ab-negative NMOSD. Furthermore, 60/65 (92\%) IgG1-positive samples had $\operatorname{IgG}(\mathrm{H}+\mathrm{L})$ endpoint titers $\geq 1: 200$, indicating that the IgG1 assay identifies not only the patients above cutoff with the anti-IgG $(\mathrm{H}+\mathrm{L})$ but also disease-relevant Abs that fall below this cutoff. These findings are consistent with a previous report that high-titer MOG-Abs were exclusively of the IgG1 isotype. ${ }^{30,36,38}$

Detection of IgM by CBA at a serum dilution of 1:20 did not distinguish different patient groups from healthy controls, limiting its diagnostic use. The flow cytometry data show that something in healthy and patient sera binds to the surface of MOGtransfected cells at low levels and is detected by anti-human $\operatorname{IgG}(\mathrm{H}+\mathrm{L})$ or IgM antibodies. This is consistent with other studies reporting high levels of MOG-IgM-Abs using immunoblot or ELISA ${ }^{1,18,39}$ and might be explained by the observation that MOG binds to components of the immune system such as C1q or DC-SIGN. ${ }^{40,41}$

The SL-MOG assay was previously shown to be negative in patients with MS and healthy controls, ${ }^{26,27}$ but here it only identified $32.3 \%$ of the IgG1 FLMOG-Abs-positive samples (see table 1). As the extracellular domains are identical in the 2 constructs, the differences in assay sensitivity may be due to expression level on the surface, glycosylation, or ability to multimerize. Two of the 21 SL-MOG-positive patients were IgM positive only. The low sensitivity of the SL-MOG assay limits its use in clinical practice.

Although this work is retrospective with limited clinical descriptions of the patients, it does suggest that the anti-IgG1/FL-MOG antibody assay can be useful in identifying MOG-Abs in patients with demyelinating diseases who are unlikely to have MS. Prospective studies with longer-term follow-up are needed to establish the clinical utility of this assay.

\section{AUTHOR CONTRIBUTIONS}

Drafting/revising the manuscript: all authors. Study concept or design: P.W. Analysis or interpretation of data: P.W., A.V. Contribution of vital reagents/tools/patients: K.C.O., M.R., D.K.S., M.J., G.T., J.R., T.T., T.M., I.N., K.F. Acquisition of data: P.W., M.W., D.K.S., A.V. Statistical analysis: P.W., A.V. Study supervision or coordination: P.W. Obtaining funding: J.P., A.V.

\section{STUDY FUNDING}

NHS National Specialised Services for Neuromyelitis Optica (P.W. M.W., J.P., M.I.L., A.V.), the Oxford Biomedical Research Centre
(M.I.L., P.W., A.V.), the ERA-net E-rare EDEN project (P.W., M.R., A.V.), KAKENHI (22229008) of The Ministry of Education, Culture, Sports, Science and Technology (MEXT) of Japan, and the Health and Labour Sciences Research Grant on Intractable Diseases (Neuroimmunological Diseases) from the Ministry of Health, Labour and Welfare of Japan (D.K.S., T.T., T.M., I.N., K.F.). M.J. received research fellowship from the Polish Ministry of Science and Higher Education program Moblinosc Plus (1070/MOB/2013/0).

\section{DISCLOSURE}

P. Waters has received speaker honoraria from Biogen Idec Japan and Euroimmun AG; has been a review editor for Frontiers in Molecular Innate Immunity; holds a patent for assays for the detection and antibodies to lGi1, Caspr2, and tag-1; and has submitted a patent for GABARR. M. Woodhall reports no disclosures. K.C. O'Connor has received travel funding and speaker honorarium from ACTRIMSCMSC and has received research support from NIH and Nancy Davis Foundation for Multiple Sclerosis. M. Riendl is an academic editor for PLOS ONE; is on the editorial board for Current Medicinal Chemistry and Autoimmune Diseases; and has received research support from Austrian Science Fund, Austrian Federal Ministry of Science, and Jubilaeumsfonds of the Austrian National Bank. M. Reindl and Medical University of Innsbruck receive payments for antibody assays (AQP4 and antineuronal antibodies) and for AQP4 antibody validation experiments organized by Euroimmun. B. Lang is a member of the Medical Committee of Mayaware; holds a patent for use of LGI1 as an antigen in detection of autoantibodies and use of GABAa gamma subunit in detection of autoantibodies; receives research support from Epilepsy Research UK; and received royalties for use of LGI1 as an antigen in detection of autoantibodies. Her department receives payment for running diagnostic assays for a range of autoantibodies. D.K. Sato has received research support from Ministry of Education, Culture, Sports, Science \& Technology (MEXT) in Japan, Japanese Government Scholarship Program, and Ichiro Kanehara Foundation. M. Juryńczyk has received research support from the Polish Ministry of Science and Higher Education. G. Tackley and J. Rocha report no disclosures. T. Takahashi has received speaker honoraria from Biogen Idec and Cosmic Corporation. T. Misu has received speaker honoraria from Bayer Schering Pharma, Biogen Idec, and Mitsubishi Pharma; has received research support from Bayer Schering Pharma, Biogen Idec Japan, Asahi Kasei Kuraray Medical Co., The Chemo-Sero-Therapeutic Research Institute, Teva Pharmaceutical K.K., Mitsubishi Tanabe Pharma Corporation, and Teijin Pharma; and has received Grants-in-Aid for Scientific Research from the Ministry of Education, Science and Technology and the Ministry of Health, Labor and Welfare of Japan. I. Nakashima has received travel funding/and or speaker honoraria from Biogen Idec Japan, Tanabe Mitsubishi, and Novartis Pharma; is an editorial board member for Multiple Sclerosis International; and received research support from LSI Medience Corporation. J. Palace has been a UK advisory board participant for Merck Serono, Bayer Schering Pharma, Biogen Idec, Teva Pharmaceutical Industries Ltd, Novartis Pharmaceuticals UK Ltd, Sanofi-Aventis, and Alexion; has received travel funding and/or speaker honoraria from ECTRIMS, Merck Serono, Novartis, Biogen Idec, Bayer Schering, and ISIS Innovation Limited, a wholly owned subsidiary of the University of Oxford; has filed a patent application to protect for the use of metabolomics as a method to diagnose and stage disease in multiple sclerosis; has consulted for Ono Pharmaceuticals Ltd, Chigai Pharma Ltd, CI Consulting, Biogen Idec, and GlaxoSmithKline; and has received research support from Bayer Schering, Merck Serono, Novartis, Department of Health, MS Society, and UK Guthy Jackson Foundation. K. Fujihara serves on scientific advisory boards for Bayer Schering Pharma, Biogen Idec, Mitsubishi Tanabe Pharma Corporation, Novartis Pharma, Chugai Pharmaceutical, Ono Pharmaceutical, Nihon Pharmaceutical, Merck Serono, Alexion Pharmaceuticals, Medimmune, and Medical Review; has received funding for travel and speaker honoraria from Bayer Schering Pharma, Biogen Idec, Eisai Inc., Mitsubishi Tanabe Pharma Corporation, Novartis Pharma, Astellas Pharma Inc., Takeda Pharmaceutical Company Limited, Asahi Kasei Medical Co., Daiichi Sankyo, Nihon Pharmaceutical, and Cosmic Corporation; is on the editorial board for Clinical and Experimental Neuroimmunology; is an advisory board member of Sri Lanka Journal of Neurology; and has received research support from Bayer 
Schering Pharma, Biogen Idec Japan, Asahi Kasei Medical, The ChemoSero-Therapeutic Research Institute, Teva Pharmaceutical, Mitsubishi Tanabe Pharma, Teijin Pharma, Chugai Pharmaceutical, Ono Pharmaceutical, Nihon Pharmaceutical, Genzyme Japan, Ministry of Education, Science and Technology of Japan, and Ministry of Health, Welfare and Labor of Japan. M.I. Leite has received travel funding and/or speaker honoraria from Biogen Idec and has received research support from NHS specialised commissioning group for neuromyelitis optica, UK and NIHR Oxford Biomedical Research Centre. A. Vincent has received travel funding and speaker honoraria from Baxter International Inc and Biogen Inc; is on the editorial board for Neurology; was an associate editor for Brain; holds a patent with Oxford University for LGI1/CASPR2 antibodies, licensed to Euroimmun AG, and for GABAAR antibodies, in negotiation with Euroimmun AG; received royalties from Athena Diagnostics, Euroimmun AG, Blackwell Publishing, and Mac Keith Press; has consulted with Athena Diagnostics; and has received research support from NIHR. Go to Neurology.org/nn for full disclosure forms.

Received December 13, 2014. Accepted in final form January 20, 2015.

\section{REFERENCES}

1. Berger T, Rubner P, Schautzer F, et al. Antimyelin antibodies as a predictor of clinically definite multiple sclerosis after a first demyelinating event. N Engl J Med 2003;349:139-145.

2. Klawiter EC, Piccio L, Lyons JA, et al. Elevated intrathecal myelin oligodendrocyte glycoprotein antibodies in multiple sclerosis. Arch Neurol 2010;67:1102-1108.

3. Zhou D, Srivastava R, Nessler S, et al. Identification of a pathogenic antibody response to native myelin oligodendrocyte glycoprotein in multiple sclerosis. Proc Natl Acad Sci USA 2006;103:19057-19062.

4. Zadro I, Brinar V, Horvat G, Brinar M. Clinical relevance of antibodies against myelin oligodendrocyte glycoprotein in different clinical types of multiple sclerosis. Clin Neurol Neurosurg 2007;109:23-26.

5. Lalive PH, Menge T, Delarasse C, et al. Antibodies to native myelin oligodendrocyte glycoprotein are serologic markers of early inflammation in multiple sclerosis. Proc Natl Acad Sci USA 2006;103:2280-2285.

6. Gaertner S, de Graaf KL, Greve B, Weissert R. Antibodies against glycosylated native MOG are elevated in patients with multiple sclerosis. Neurology 2004;63:2381-2383.

7. Markovic M, Trajkovic V, Drulovic J, et al. Antibodies against myelin oligodendrocyte glycoprotein in the cerebrospinal fluid of multiple sclerosis patients. J Neurol Sci 2003;211:67-73.

8. Reindl M, Linington $\mathrm{C}$, Brehm U, et al. Antibodies against the myelin oligodendrocyte glycoprotein and the myelin basic protein in multiple sclerosis and other neurological diseases: a comparative study. Brain 1999;122: 2047-2056

9. Bernard CC, Johns TG, Slavin A, et al. Myelin oligodendrocyte glycoprotein: a novel candidate autoantigen in multiple sclerosis. J Mol Med (Berl) 1997;75:77-88.

10. Xiao BG, Linington C, Link H. Antibodies to myelinoligodendrocyte glycoprotein in cerebrospinal fluid from patients with multiple sclerosis and controls. J Neuroimmunol 1991;31:91-96.

11. Haase CG, Schmidt S. Detection of brain-specific autoantibodies to myelin oligodendrocyte glycoprotein, S100beta and myelin basic protein in patients with Devic's neuromyelitis optica. Neurosci Lett 2001;307:131-133.

12. Pittock SJ, Reindl M, Achenbach S, et al. Myelin oligodendrocyte glycoprotein antibodies in pathologically proven multiple sclerosis: frequency, stability and clinicopathologic correlations. Mult Scler 2007;13:7-16.
13. Karni A, Bakimer-Kleiner R, Abramsky O, Ben-Nun A. Elevated levels of antibody to myelin oligodendrocyte glycoprotein is not specific for patients with multiple sclerosis. Arch Neurol 1999;56:311-315.

14. Lim ET, Berger T, Reindl M, et al. Anti-myelin antibodies do not allow earlier diagnosis of multiple sclerosis. Mult Scler 2005;11:492-494.

15. Wang H, Munger KL, Reindl M, et al. Myelin oligodendrocyte glycoprotein antibodies and multiple sclerosis in healthy young adults. Neurology 2008;71:1142-1146.

16. Pelayo R, Tintoré M, Montalban X, et al. Anti-myelin antibodies with no progression to multiple sclerosis. $\mathrm{N}$ Engl J Med 2007;356:426-428.

17. Kuhle J, Pohl C, Mehling M, et al. Lack of association between anti-myelin antibodies and progression to multiple sclerosis. N Engl J Med 2007;356:371-378.

18. Lampasona V, Franciotta D, Furlan R, et al. Similar low frequency of anti-MOG IgG and IgM in MS patients and healthy subjects. Neurology 2004;62:2092-2094.

19. Dale RC, Tantsis EM, Merheb V, et al. Antibodies to MOG have a demyelination phenotype and affect oligodendrocyte cytoskeleton. Neurol Neuroimmunol Neuroinflamm 2014; 1:e12; doi: 10.1212/NXI.0000000000000012.

20. Ikeda K, Kiyota N, Kuroda H, et al. Severe demyelination but no astrocytopathy in clinically definite neuromyelitis optica with anti-myelin-oligodendrocyte glycoprotein antibody. Mult Scler Epub 2014 Sep 25.

21. Marta CB, Bansal R, Pfeiffer SE. Microglial Fc receptors mediate physiological changes resulting from antibody cross-linking of myelin oligodendrocyte glycoprotein. J Neuroimmunol 2008;196:35-40.

22. von Büdingen HC, Hauser SL, Fuhrmann A, et al. Molecular characterization of antibody specificities against myelin/oligodendrocyte glycoprotein in autoimmune demyelination. Proc Natl Acad Sci USA 2002;99:8207-8212.

23. Marta CB, Oliver AR, Sweet RA, Pfeiffer SE, Ruddle NH. Pathogenic myelin oligodendrocyte glycoprotein antibodies recognize glycosylated epitopes and perturb oligodendrocyte physiology. Proc Natl Acad Sci USA 2005;102: 13992-13997.

24. O’Connor KC, McLaughlin KA, De Jager PL, et al. Selfantigen tetramers discriminate between myelin autoantibodies to native or denatured protein. Nat Med 2007;13: 211-217.

25. Kitley J, Woodhall M, Waters P, et al. Myelin-oligodendrocyte glycoprotein antibodies in adults with a neuromyelitis optica phenotype. Neurology 2012;79:1273-1277.

26. Kitley J, Waters P, Woodhall M, et al. Neuromyelitis optica spectrum disorders with aquaporin-4 and myelinoligodendrocyte glycoprotein antibodies: a comparative study. JAMA Neurol 2014;71:276-283.

27. Sato DK, Callegaro D, Lana-Peixoto MA, et al. Distinction between MOG antibody-positive and AQP4 antibody-positive NMO spectrum disorders. Neurology 2014;82:474-481.

28. Reindl M, Di Pauli F, Rostasy K, Berger T. The spectrum of MOG autoantibody-associated demyelinating diseases. Nat Rev Neurol 2013;9:455-461.

29. Rostásy K, Mader S, Hennes EM, et al. Persisting myelin oligodendrocyte glycoprotein antibodies in aquaporin-4 antibody negative pediatric neuromyelitis optica. Mult Scler 2013;19:1052-1059.

30. Mader S, Gredler V, Schanda K, et al. Complement activating antibodies to myelin oligodendrocyte 
glycoprotein in neuromyelitis optica and related disorders. J Neuroinflammation 2011;8:184.

31. Ramanathan S, Reddel SW, Henderson A, et al. Antibodies to myelin oligodendrocyte glycoprotein in bilateral and recurrent optic neuritis. Neurol Neuroimmunol Neuroinflamm 2014;1:e40; doi: 10.1212/NXI.0000000000000040.

32. Mayer MC, Breithaupt C, Reindl M, et al. Distinction and temporal stability of conformational epitopes on myelin oligodendrocyte glycoprotein recognized by patients with different inflammatory central nervous system diseases. J Immunol 2013;191:3594-3604.

33. Rostasy K, Mader S, Schanda K, et al. Anti-myelin oligodendrocyte glycoprotein antibodies in pediatric patients with optic neuritis. Arch Neurol 2012;69:752-756.

34. Kezuka T, Usui Y, Yamakawa N, et al. Relationship between NMO-antibody and anti-MOG antibody in optic neuritis. J Neuroophthalmol 2012;32:107-110.

35. Brilot F, Dale RC, Selter RC, et al. Antibodies to native myelin oligodendrocyte glycoprotein in children with inflammatory demyelinating central nervous system disease. Ann Neurol 2009;66:833-842.
36. Probstel AK, Dornmair K, Bittner R, et al. Antibodies to MOG are transient in childhood acute disseminated encephalomyelitis. Neurology 2011;77:580-588.

37. Waters PJ, McKeon A, Leite MI, et al. Serologic diagnosis of NMO: a multicenter comparison of aquaporin-4- $\operatorname{IgG}$ assays. Neurology 2012;78:665-671.

38. McLaughlin KA, Chitnis T, Newcombe J, et al. Agedependent $\mathrm{B}$ cell autoimmunity to a myelin surface antigen in pediatric multiple sclerosis. J Immunol 2009;183: 4067-4076.

39. Egg R, Reindl M, Deisenhammer F, Linington C, Berger T. Anti-MOG and anti-MBP antibody subclasses in multiple sclerosis. Mult Scler 2001;7:285-289.

40. Johns TG, Bernard CC. Binding of complement component $\mathrm{Clq}$ to myelin oligodendrocyte glycoprotein: a novel mechanism for regulating CNS inflammation. Mol Immunol 1997;34:33-38.

41. García-Vallejo JJ, Ilarregui JM, Kalay H, et al. CNS myelin induces regulatory functions of DC-SIGN-expressing, antigen-presenting cells via cognate interaction with MOG. J Exp Med 2014;211:1465-1483. 


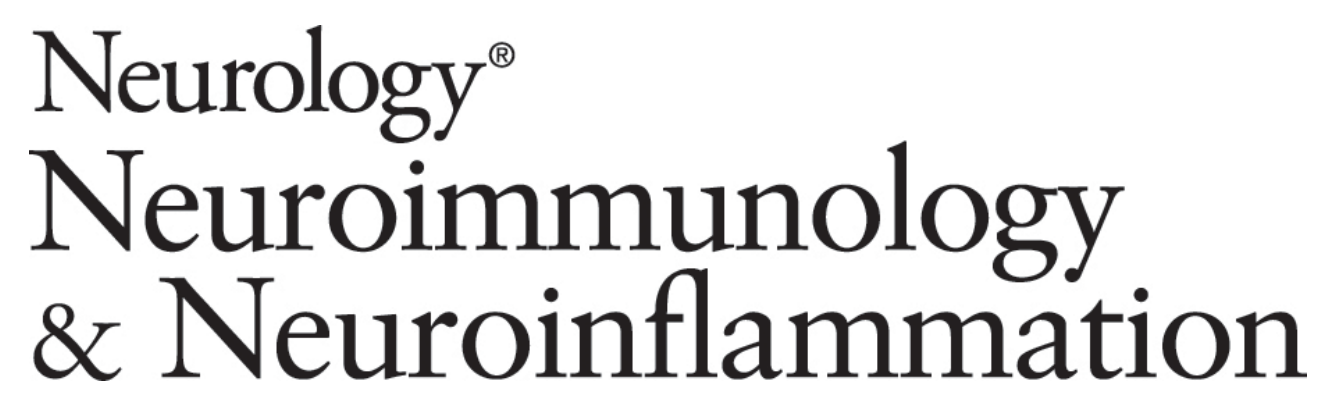

MOG cell-based assay detects non-MS patients with inflammatory neurologic disease Patrick Waters, Mark Woodhall, Kevin C. O'Connor, et al.

Neurol Neuroimmunol Neuroinflamm 2015;2;

DOI 10.1212/NXI.0000000000000089

This information is current as of March 19, 2015

Neurol Neuroimmunol Neuroinflamm is an official journal of the American Academy of Neurology.

Published since April 2014, it is an open-access, online-only, continuous publication journal. Copyright $\odot$ 2015 American Academy of Neurology. All rights reserved. Online ISSN: 2332-7812.

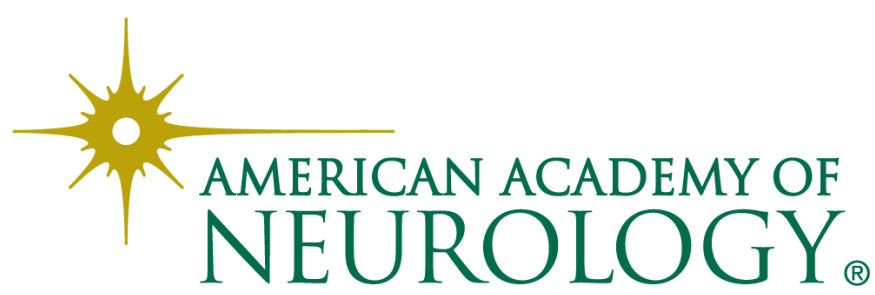




\section{Updated Information \&} Services

\section{Supplementary Material}

\section{References}

Citations

Subspecialty Collections

Permissions \& Licensing

Reprints including high resolution figures, can be found at: http://nn.neurology.org/content/2/3/e89.full.html

Supplementary material can be found at: http://nn.neurology.org/content/suppl/2015/03/19/2.3.e89.DC1

This article cites 40 articles, 7 of which you can access for free at: http://nn.neurology.org/content/2/3/e89.full.html\#\#ref-list-1

This article has been cited by 16 HighWire-hosted articles: http://nn.neurology.org/content/2/3/e89.full.html\#\#otherarticles

This article, along with others on similar topics, appears in the following collection(s):

\section{Acute disseminated encephalomyelitis}

http://nn.neurology.org//cgi/collection/acute_disseminated_encephalo myelitis

Devic's syndrome

http://nn.neurology.org//cgi/collection/devics_syndrome

Multiple sclerosis

http://nn.neurology.org//cgi/collection/multiple_sclerosis

Information about reproducing this article in parts (figures,tables) or in its entirety can be found online at:

http://nn.neurology.org/misc/about.xhtml\#permissions

Information about ordering reprints can be found online: http://nn.neurology.org/misc/addir.xhtml\#reprintsus

Neurol Neuroimmunol Neuroinflamm is an official journal of the American Academy of Neurology.

Published since April 2014, it is an open-access, online-only, continuous publication journal. Copyright $\odot$ 2015 American Academy of Neurology. All rights reserved. Online ISSN: 2332-7812.

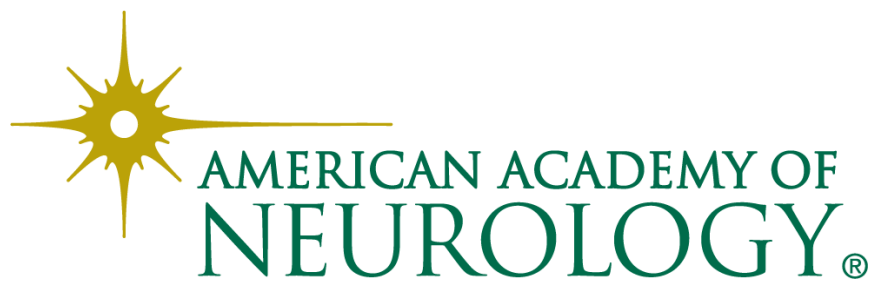

